- The development of porcelain veneers

- Longevity and factors affecting it

- Tooth preparation, and management of existing restorations

- Impression recording and temporisation (in those few cases which require it)

- Try in, bonding and finishing

- Non-standard porcelain veneers

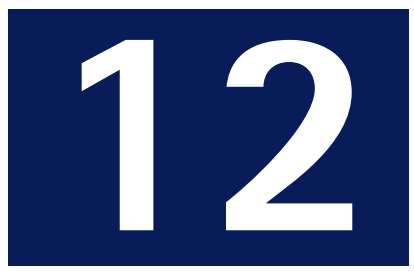

\title{
Crowns and other extra-coronal restorations: Porcelain laminate veneers
}

\author{
A. W. G. Walls ${ }^{1}$ J. G. Steele ${ }^{2}$ and R. W. Wassell ${ }^{3}$
}

Porcelain veneers are resin-bonded to the underlying tooth and provide a conservative method of improving appearance or modifying contour, without resorting to a full coverage crown. The porcelain laminate veneer is now a frequently prescribed restoration for anterior teeth. The sums spent by the Dental Practice Board on this type of treatment increased from quarter of a million pounds in 1988/89 to over seven million in 1994/95, ${ }^{1}$ representing some 113,582 treatments. Since that time the number has stabilised at over 100,000 veneers prescribed each year. ${ }^{2}$ The objective of this paper is to give a practical guide on providing these restorations.

CROWNS AND EXTRA-CORONAL RESTORATIONS:

1. Changing patterns and the need for quality

2. Materials considerations

3. Pre-operative assessment

4. Endodontic considerations

5. Jaw registration and articulator selection

6. Aesthetic control

7. Cores for teeth with vital pulps

8. Preparations for full veneer crowns

9. Provisional restorations

10. Impression materials and technique

11. Try-in and cementation of crowns

\section{Porcelain veneers}

13. Resin bonded metal restorations

${ }^{1 *}$ Professor of Restorative Dentistry, 2,3Senior Lecturer in Restorative Dentistry, Department of Restorative Dentistry, The Dental School, Newcastle upon Tyne NE2 4BW;

${ }^{*}$ Correspondence to: Prof A. W. G. Walls, Department of Restorative Dentistry, The Dental School, University of Newcastle upon Tyne, Newcastle upon Tyne NE2 4BW E-mail:a.w.g.walls@ncl.ac.uk

\section{Refereed Paper}

๑ British Dental Journal 2002; 193 :

73-82
Whenever possible guidelines for provision of porcelain laminate veneers are based on data from the dental literature, but where this is not possible they will be based on our clinical experience and practice. Veneers are often placed on the buccal aspect of maxillary anterior teeth but other applications are possible and these are described at the end of the article.

\section{HISTORY}

The concept of veneering was first described in the dental literature some time ago, ${ }^{3}$ although it is only with the advent of efficient bonding of resins to enamel and dentine and the use of etched, coupled porcelain surfaces that aesthetically pleasing, durable and successful restorations can be made. ${ }^{4}$ These restorations are now an accepted part of the dentist's armamentarium. ${ }^{5-7}$ Custom-made acrylic resin veneers preceded them, but these showed unacceptable levels of failure and of marginal stain. ${ }^{8}$ Alternative veneering materials are still available, usually either direct or indirect composite resin materials. However, these may suffer from degradation of surface features and accretion of surface stain with time. ${ }^{9-11}$

Porcelain veneers have traditionally been made from aluminous or reinforced feldspathic porcelains, which have relatively poor strength in themselves but produce a strong structure when bonded to enamel. Porcelain veneers can be made from most of the high strength ceramics discussed in the second article of the series. Such materials may hold promise for the future. A study of 83 IPS Empress veneers placed over a 6-year period in private practice reported only one failure, but as yet there are no clinical data making a direct comparison between these and the traditional materials.

That the strength of traditional porcelain is generally adequate for anterior porcelain veneers is supported by a number of clinical studies. Some authors ${ }^{9,12-17}$ have reported low rates of failure because of the loss of retention and fracture $(0-5 \%)$ with short and mediumterm studies of up to 5 years. Indeed, a long-term follow-up ${ }^{18}$ of veneers placed over a 10-year period shows a survival rate of $91 \%$ at 10.5 years (calculated with the Kaplan Meyer method). These excellent results may, amongst other things, reflect careful case selection, but it is worth noting that other authors, ${ }^{5,13,19,20}$ have reported much higher rates of failure of between $7-14 \%$ over $2-5$ years. Such studies suggest that the risk factors for veneer failure are:

- Bonding onto pre-existing composite restorations (which is considered later)

- Placement by an inexperienced operator

- Using veneers to restore worn or fractured teeth where a combination of parafunction, large areas of exposed dentine and insufficient tooth tissue exist.

Another risk factor, shown up by in-vitro work, is the tendency for thermal changes in combination with polymerisation contraction stresses to cause cracking of the veneer when the porcelain is thin and the luting composite thick. ${ }^{21}$ A thick composite lute may occur as a result of a poorly fitting veneer or the use of copious die spacer in an attempt to mask underlying tooth discolouration. Least cracking was seen with a ceramic and luting composite thickness ratio above 3 . 
Fig. $1 \mathrm{~A} 1 \mathrm{~mm}$ round diamond bur being used to create depth marks on the buccal surface of UR1 (11)

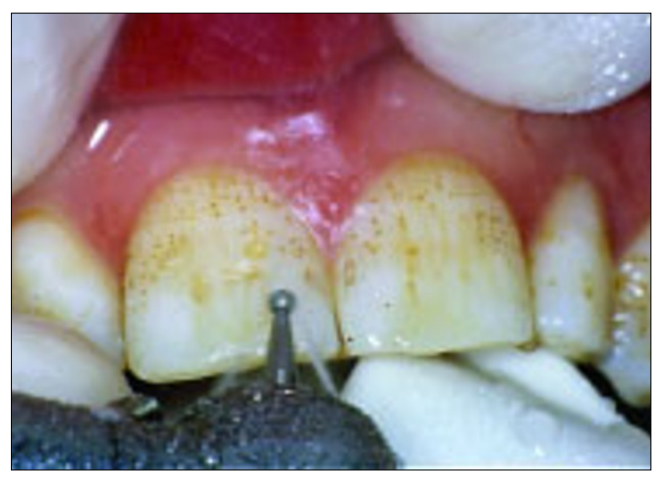

In-vivo, minor chipping and cracking may be smoothed or repaired without the need to remove the whole veneer. Dunne and Millar reported that the incidence of such repairable defects $(8 \%)$ was similar to the number of veneers requiring total replacement $(11 \%){ }^{5}$

It is useful to be aware of the above data when patients ask how long their proposed veneers are likely to last. It may also be prudent to warn them that although most $(80-100 \%)^{7}$ patients remain satisfied with the aesthetics, veneers are prone to marginal staining, the amount of which will vary from patient to patient. Staining may be caused by one or more of the following:

- Microleakage at the cervical margin, especially where located in aprismatic enamel or, worse still, dentine

- Wear and submargination of the luting composite, especially with an open margin

- Marginal excess of luting composite

To some extent, these factors can be controlled or influenced by careful attention to clinical technique.

\section{CLINICAL TECHNIQUE}

A key element in success with porcelain veneers is carefully controlled but appropriate tooth tissue reduction. ${ }^{22-24}$ The aims of tooth preparation are to:

- Provide some space into which the technician can build porcelain without over-contouring the tooth

- Provide a finished preparation that is smooth and has no sharp internal line-angles which would give areas of high stress concentration in the restoration

- Maintain the preparation within enamel whenever possible

- Define a finish line to which the technician can work.

It may be possible to prepare veneer preparations without local anaesthetic. However, in our experience, sub-gingival margin placement, inadvertent dentine exposure and the unpleasant coldness from the water spray and aspirator usually make its use advisable.

\section{Depth of preparation}

It is desirable for the tooth preparation to remain within enamel so careful control of preparation depth is important. Obviously, the enamel thick- ness varies from the incisal edge to the cervical margin. Hence the preparation depth will need to vary over the length of the tooth to avoid (if possible) exposing dentine. The preparation depth should be of the order of $0.4 \mathrm{~mm}$ close to the gingival margin, rising to $0.7 \mathrm{~mm}$ for the bulk of the preparation. This is best achieved by using a depth mark of some sort. In our experience formal depth grooves can be of limited value in this area as there is a tendency for the bur to catch and run into the groove during buccal reduction, accentuating the groove. The alternative is to use depth pits prepared on the surface of the tooth using a 1 mm diameter round bur sunk to half its diameter (Fig. 1). The buccal surface reduction can then be undertaken to join the base of the pits. The reduction should mimic the natural curvature of the tooth in order to provide an even thickness of porcelain layer over the tooth surface, hence it should be in at least two planes. ${ }^{24}$

When the tooth concerned is markedly discoloured, it is sensible to undertake a greater level of reduction to give the technician more chance to mask the underlying stain without over-contouring the tooth. This will have obvious disadvantages, as the preparation is likely to extend into dentine with greater depth of tooth reduction.

Nattrass et al. ${ }^{25}$ have demonstrated that even with experienced operators and careful control of cutting instruments there is a tendency for dentine to be exposed in the cervical and proximal regions of the preparations, where the enamel is thinnest. This should be borne in mind when deciding on the type of luting agent to be used in veneer placement. They also found that there was a tendency for variations in tooth preparation depth across their samples with least reduction in the mid-incisal region. There is no suggestion in the literature as yet that this causes any long-term damage to the tooth or affects the longevity of the veneer.

\section{Incisal edge reduction}

One important decision to make before commencing the preparation is whether or not the incisal edge of the tooth is to be reduced. There are four basic preparation designs that have been described for the incisal edge (Fig. 2):

- Window, in which the veneer is taken close to but not up to the incisal edge. This has the advantage of retaining natural enamel over the incisal edge, but has the disadvantage that the incisal edge enamel is weakened by the preparation. Also, the margins of the veneer would become vulnerable if there is incisal edge wear whilst the incisal lute can be difficult to hide.

- Feather, in which the veneer is taken up to the height of the incisal edge of the tooth but the edge is not reduced. This has the advantage that once again guidance on natural tooth is maintained but the veneer is liable to be fragile at the incisal edge and may be subject to $\mathrm{peel} / \mathrm{sheer}$ forces during protrusive guidance.

- Bevel, in which a bucco-palatal bevel is prepared across the full width of the preparation 
and there is some reduction of the incisal length of the tooth. This gives more control over the incisal aesthetics and a positive seat during try in and luting of the veneer. The margin is not in a position that will be subjected to direct shear forces except in protrusion. However, this style of preparation does involve more extensive reduction of tooth tissue.

- Incisal overlap, in which the incisal edge is reduced and then the veneer preparation extended onto the palatal aspect of the preparation. This also helps to provide a positive seat for luting whilst involving more extensive tooth preparation. This style of preparation will also modify the path of insertion of the veneer which will have to be seated from the buccal/incisal direction rather than the buccal alone. Care needs to be taken to ensure that any proximal wrap around of the preparation towards the gingival margin does not produce an undercut to the desired path of insertion for the veneer. It may be necessary to rotate such veneers into place by locating the incisal edge first then rotating the cervical margin into position.

There is little data available upon which to base a decision over incisal edge preparation. Hui et $a l .{ }^{26}$ demonstrated that veneers in window preparations were best able to resist incisal edge loading and that an overlap design fractured at the lowest loads. However, the magnitude of loading at which the overlap design veneers failed was much greater than that encountered clinically for such teeth. Furthermore, a clinical study was unable to distinguish any difference in failure rate between incisal preparation designs after two and a half years of service. $^{27}$ If the operator intends to either improve the incisal edge aesthetics or to increase the length of a tooth then either an overlap or bevel design would be the preparation of choice. If it were not necessary to extend the incisal edges, then it may be possible to use a featheredge design, however the operator has less control of incisal edge aesthetics with this approach. Nordbo et al. ${ }^{14}$ report no failures but 5\% incisal chipping at 3-years for veneers placed using a feather-edge design and 0.3 to $0.5 \mathrm{~mm}$ buccal tooth reduction.

The authors would not recommend the buccal window, as it is very difficult to mask the incisal finish line of the restoration. As this style of restoration is used to improve the appearance of teeth, the introduction of an aesthetic defect would be inappropriate. If the incisal edge is to be modified then the length should be reduced by some $0.5-0.75 \mathrm{~mm}^{28}$ to allow adequate strength within the porcelain incisal edge without elongating the tooth. Depth grooves can be used to monitor accurately incisal edge reduction (Fig. 1); we would strongly recommend this approach.

\section{Axial tooth reduction}

Axial tooth reduction is best undertaken using diamond burs in either an airotor or a speed

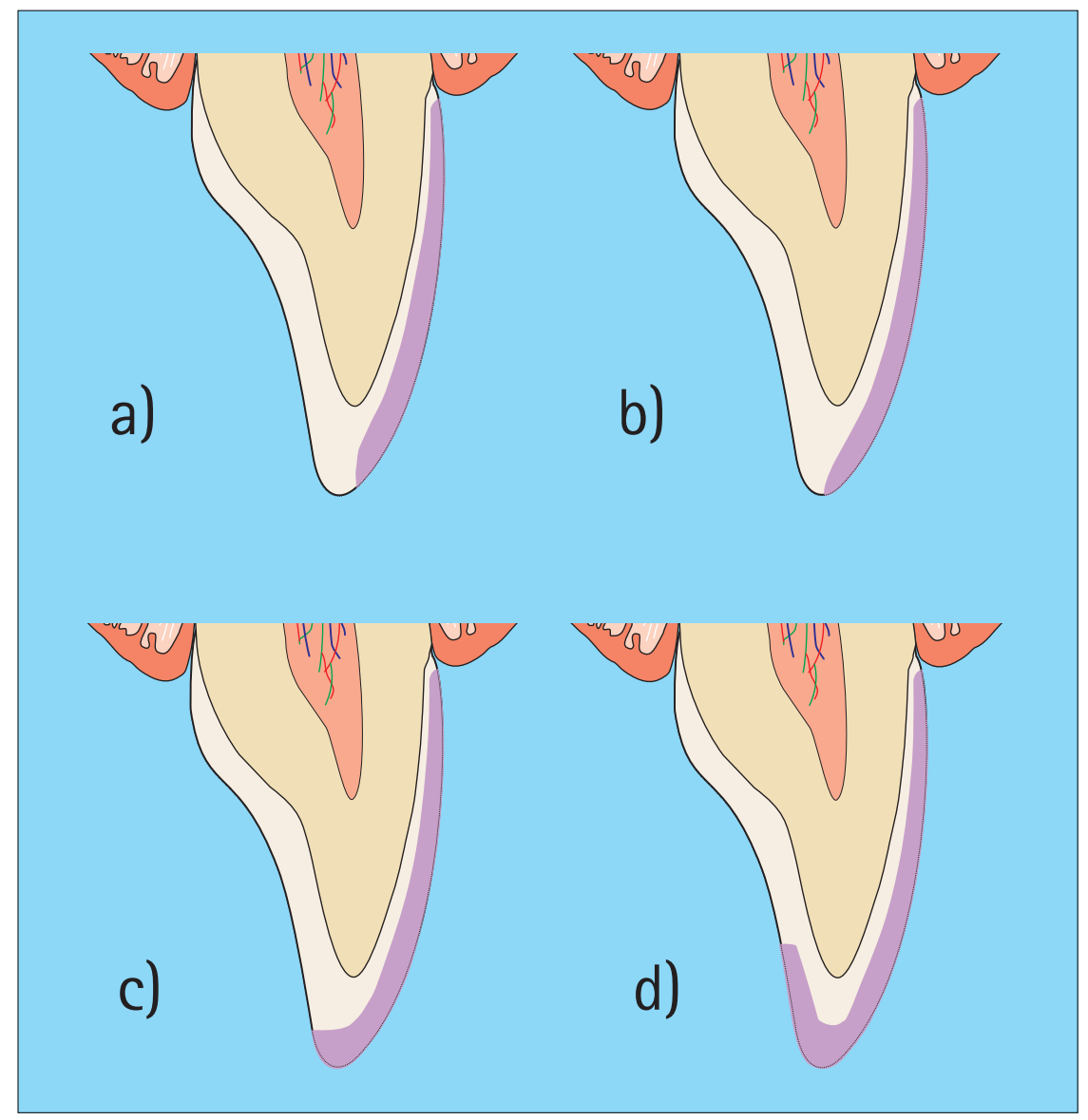

Fig. 2 Four incisal preparations are possible for veneers: a) window , b) feather , c) bevel or d) incisal overlap

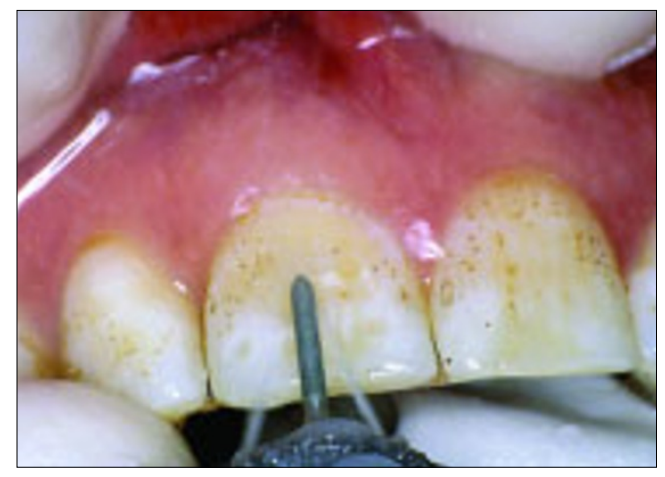

accelerating handpiece with a conventional motor. It is easier to achieve predictable tooth reduction using either a parallel sided or tapered bur with straight sides rather than a flameshaped bur (Fig. 3). Some clinicians advocate preparing the gingival finish line as the first step using a round diamond bur of appropriate diameter, which will automatically produce a chamfered finish line. Alternatively a torpedo shaped bur can be used to produce both the axial reduction and the gingival finish line (Fig. 4), which is the method we prefer.

Conventional diamond burs leave a macroscopically roughened surface on enamel. Further preparation of the tooth using either a small particle size diamond bur or a multi-fluted tungsten carbide finishing bur will smooth the surface of the preparation and can be used to refine the finishing margin. At this stage the gingival tissues
Fig. 3 Straight sided torpedo-shaped diamond bur provides more predictable axial reduction in association with depth marks than a flame-shaped bur 
Fig. 4 The torpedo bur can also be used to create the gingival bevel

Fig. 5 A flat plastic instrument protects the gingivae during finishing of the chamfer with a multi-fluted tungsten carbide bur. A speed accelerating handpiece provides greater control than an airotor
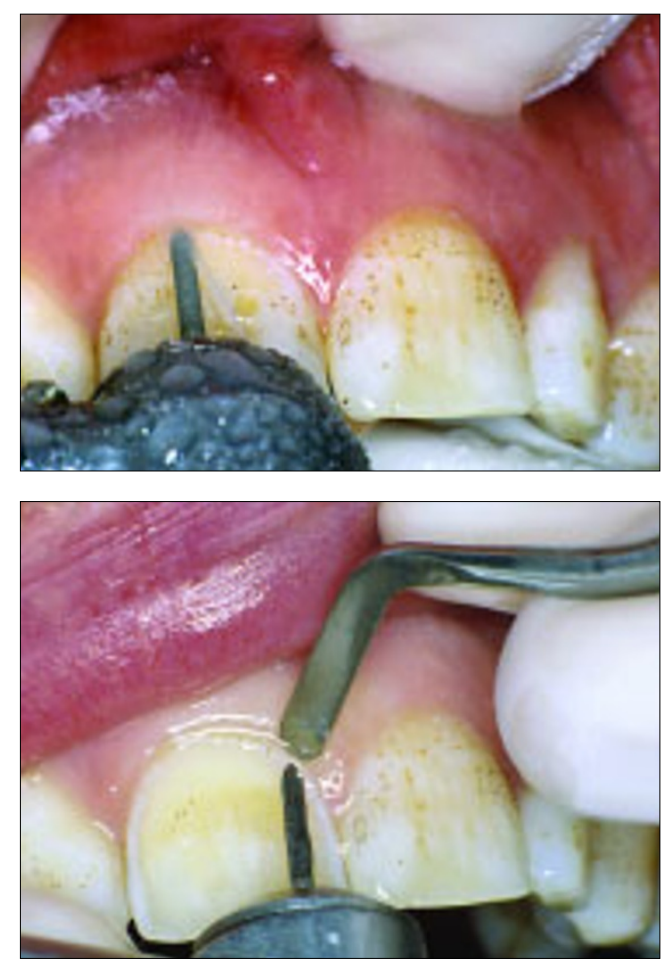

can be protected from damage using a flat plastic instrument (Fig. 5) or gingival retraction cord can be packed for the same purpose, which will in turn facilitate the impression. It is often impractical to provide provisional restorations for porcelain veneers (see later) but some patients are conscious of the roughened tooth surface in their mouths, which should be smoothed.

\section{Proximal finish lines}

It is best if the proximal finishing margins for the preparation do not extend beyond the contact point in the incisal third of the tooth - in other words, the contact point with adjacent teeth should be maintained. If it proves necessary to prepare through the contact area then some form of provisional restoration would be required to prevent inadvertent tooth movement between tooth preparation and fitting of the veneers. Cervically it may be necessary to extend the preparation into the gingival embrasure to mask discoloured tooth substance in the proximal zone immediately above the interdental papilla. Care must be used not to create an undercut preparation in this area to the proposed path of insertion of the restoration.

It is usually necessary to trim the proximal finish line with a chisel to avoid the sharp lip of enamel that often results from being unable to take the bur to the very edge of the preparation. In this respect it is better to change to a smaller diameter bur to prepare the proximal margins of a single tooth being veneered to permit limited tooth reduction without damaging the adjacent tooth.

\section{Cervical finish lines}

The cervical finish lines for a veneer should be a chamfer with about a $0.4 \mathrm{~mm}$ maximum depth.
The rounded internal line angle will help to reduce stresses in the margin of the veneer that may otherwise develop during firing. Also, porcelain will adapt more readily to this shape during manufacture. The finish line should lie just at the crest of the free gingival margin, unless the veneers are being used to mask severe staining when greater sub-gingival extension may be required for aesthetic reasons. This position for the gingival extension of the veneer usually gives the best compromise between aesthetic control of the finished restoration and the ease with which the clinician can control moisture during luting.

It is helpful to have a defined cervical finishing margin so that the porcelain technician will be able to identify clearly the desired extent of the veneer. However, there is a tendency for the cervical margins of finished veneers to be overbulked to give greater durability during clinical handling. These margins should therefore be thinned as well as finished after luting.

\section{Coping with pre-existing restorations}

Some teeth that require veneers will have existing composite resin restorations in place. There are two ways to deal with this:

- Bond to a prepared composite resin surface. This is difficult, particularly if the composite restoration has been in place for any length of time. Water sorption, exposed un-silanated surfaces of filler particles and limited opportunities for further polymerisation of the resin component of the set material all contribute to a reduced bond strength.

- Replace the restoration. This can be done relatively easily, but should be done at the visit when the veneer is luted to the tooth so the new composite has the best chance of bonding to the porcelain veneer as well as the tooth tissue. This makes the procedure for bonding the veneer more complex. The old restoration needs to be removed before the veneer is attached to the tooth. The veneer is then luted in place using the requisite bonding system and subsequently the composite resin restoration replaced in the same manner as when placing a conventional Class III or IV composite filling. It can be difficult to avoid producing overhanging margins using this technique, so care is required to ensure that any such overhangs are identified and eliminated.

One of the causes for failure that Dunne and Millar ${ }^{5}$ identified was that veneers were attached to pre-existing restorations. It would seem sensible to replace such restorations at the time of veneer placement to reduce this as a possible cause of early failure of the veneer. Alternatively, if there are extensive restorations present it may be more sensible to provide a crown.

\section{Recording an impression}

Impression technique and soft tissue handling are dealt with elsewhere in this series, so we will not go into great detail here. However it is 
appropriate to use short sections of retraction cord around the margins of the preparations to facilitate the capture of both the finishing edge of the preparation and the adjacent area of unprepared tooth. Electro-surgery is best avoided because of the risk of gingival recession revealing the veneer margin.

An impression of the opposing arch is indispensable if the incisal edges of the veneers are involved in guidance.

\section{Laboratory prescription and manufacture}

Again, communication with your technician and achieving maximum aesthetics is covered elsewhere in this series. Of particular importance in relation to veneers is careful shade selection, especially if you are planning to modify the colour of the tooth. If you intend to attempt to modify the shade of the veneer with the luting agent then it is sensible to ask the technician to provide space for the luting resin using a proprietary die-spacing system but bear in mind that the porcelain should not be so thin that there is a risk of it being cracked by the thick composite lute. ${ }^{21}$ In addition, if a diagnostic wax-up has been used to demonstrate a modification in anterior aesthetics then this should be sent to the laboratory as well. It can also be beneficial to send a study cast of the teeth prior to preparation if one is available should you want to preserve the original tooth form.

There are a variety of methods for manufacture of porcelain veneers using either a refractory die material, a platinum matrix laid down on a conventional working model or one of the castable ceramic materials prepared using the lost wax technique. Sim and Ibbetson ${ }^{29}$ have shown that the best quality of marginal fit was obtained with a platinum foil system, followed by a refractory die and that the worst fit was associated with cast glass restorations.

It is best to ask your laboratory for the veneer to be etched with hydrofluoric acid but not to apply the silane-coupling agent. These agents need to be applied just prior to luting the veneer in place (whether or not the laboratory has applied silane) and are provided in most commercially available resin luting kits. Too early an application of a coupling agent, or contamination of the coupling agent coated surface prior to bonding can reduce the strength of the attachment between resin and veneer. Also, two component silane systems must not be kept after mixing as the silane polymerises to an unreactive polysiloxane, again with a reduction in bond strength. ${ }^{7}$

\section{Provisional restorations}

It is difficult and time-consuming to provide provisional restorations for teeth prepared for porcelain veneers. It is often best simply to leave the teeth in their prepared state providing the patient is aware that this is going to happen and the teeth are not sensitive.

A variety of techniques have been described for placement of provisional restorations if they are required. These include directly placed composite resin veneers and producing a transparent matrix from a thermoplastic material to allow multiple composite veneers to be made simultaneously. ${ }^{30}$ Such provisional restorations need to be attached to the enamel surface and the only practical way to do this is using the acid etch technique. Obviously, only a very small area of enamel in the centre of the preparation should be spot-etched to provide attachment for the composite resin, which can then be removed easily during the next visit without damaging the periphery of the preparation. It is best to avoid the margins of the preparations when doing this with spot etching at the centre only.

Provisional restorations should be made with care, avoiding gingival excess. Any such excess would cause gingival irritation whilst the veneers are being made and may result in an alteration of the position of the gingival margin or cause difficulty with bleeding during luting.

Provisional restorations are useful when you plan to alter the position of the teeth using veneers. The diagnostic wax-up can be used to prepare a thermoplastic matrix. This matrix is then used to make composite resin veneers directly in the mouth. This will allow the patient to experience the planned changes to their teeth at first hand and to approve the change in their appearance before the definitive restorations are made, avoiding a potential cause for grievance.

Trial placement. The veneers should be returned from the laboratory in a foam-lined box rather than on the working model of the patient. It is important that neither you nor the laboratory place the etched veneers back on the stone dies. Any contact between the etched porcelain surface and dental stone will result in abrasion of the stone model and some stone dust becoming trapped in the delicate veneer surface. Swift et al. ${ }^{31}$ have shown that such contamination results in a substantial fall in the bond strength between veneer and resin. They also found that it was very difficult to clean an etched porcelain surface that has been contaminated with dental stone.

Handling porcelain veneers can be difficult; they are small and delicate. There are commercially available devices to help with this, either in the form of a tiny suction cup or a small rod with a tacky resin at one end. Alternatively a little piece of ribbon wax on the end of an amalgam plugger makes a useful substitute.

Check the quality of fit and gingival extension of the veneer against the tooth, which should have been cleaned with pumice in water prior to the trial. Once you are happy that the quality of fit is acceptable, the next stage is to assess the colour match. The colour of a porcelain veneer cannot be assessed if the veneer is simply placed on the surface of the tooth. Much of the overall colour for the final restoration comes from the tooth structure, so a colour-coupling agent is needed between the tooth and the veneer (Fig. 6).

In its simplest form water will allow the colour of the tooth to be expressed through the 
Fig. 6 The advantages of using a colour-coupling agent are seen here. The veneer at UL1(21) looks relatively translucent (try-in paste used) compared with the opaque UR1(11) (no try-in paste used)

Fig. 7 Prior to curing the luting agent, excess material must be removed from the margin of the veneer and the gingival crevice. Note the small sections of Melamine ${ }^{\circledR}$ matrix used to prevent the luting agent from bonding teeth together
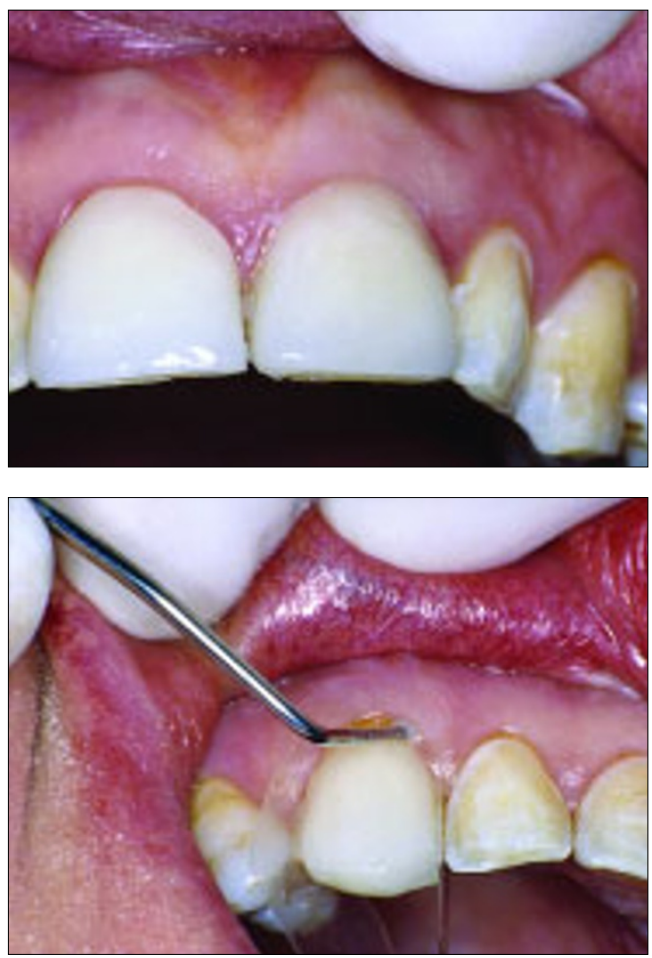

veneer and give a reasonable guide to the overall appearance if a neutral coloured luting resin is to be used.

If it is necessary to try to modify the colour of the finished restoration using the luting resin then the veneer must be tried in with an appropriate colour of paste. This can either be the luting agent itself or, alternatively, some manufacturers provide trial pastes that will not set but have similar optical properties to the luting resin. If the definitive luting resin is used great care must be taken to ensure that the resin does not set under the action of the operating light and that the paste used for the trial is removed completely from the veneer. Some manufacturer's trial pastes are water-soluble making their removal relatively straightforward. However if a resin based trial paste is used this needs to be removed using an organic solvent. Swift et al. ${ }^{31}$ found that acetone, an agent that has often been suggested and used for this role, produces markedly reduced bond strengths. A more acceptable alternative would be ethanol. Once the quality of fit of the veneer and the shade of the luting paste have been assessed the etched surface of the porcelain should be coated with a silane coupling agent, following the manufacturer's instructions for the product chosen.

\section{Luting the veneer}

Having established that the veneer is of an appropriate shade, or can be modified with a luting resin to be satisfactory, it is ready to be bonded to the supporting enamel and dentine. In view of the reported high prevalence of dentine exposure on veneer preparations ${ }^{25}$ we would advise the routine use of a dentine bonding agent.

Good moisture control is critical if adhesive techniques are to work. Contamination of either the prepared tooth surface or the veneer fitting surface with saliva, blood or crevicular fluid will result in reduced bond strengths. Moisture control can be achieved using rubber dam, but where this is impractical gingival retraction cord can be a helpful adjunct to prevention of contamination from the gingival crevice. The residual enamel should be cleaned using pumice and water and then etched, washed and dried. Details of technique will not be given here, as they are so material specific. It can be tempting to cut corners during this stage, but it is vital that you use the luting resins as the manufacturer suggests to achieve optimal results.

Having applied the dentine/enamel bonding system the veneer should be loaded with luting resin and located on the surface of the tooth. At this stage the excess of unset resin around the periphery of the veneer can best be removed using a metal instrument (Fig. 7) or a brush dipped in unfilled resin. Removal needs to be undertaken with care, as there is a tendency for resin to be pulled out from the periphery of the lute space leaving sub-margination, particularly if dental floss is used.

Once all gross excess is removed the luting resin can be cured using a visible light activation unit. It is essential to ensure an adequate exposure to cure fully the luting resin through the porcelain veneer. Most manufacturers' guidelines suggest 30-40s cure times. This is inadequate with research suggesting that 60s is more realistic. ${ }^{32-34}$

Light-activation of a luting agent through an opaque veneer or one of greater than $0.7 \mathrm{~mm}$ thickness, is not adequately effective. ${ }^{35}$ In these circumstances a dual-curing resin, which is initiated both by admixing the pastes to give a chemical set and by visible-light activation, should be used. Such dual-cure agents should not be used on thinner veneers as they do not polymerise as effectively as a visible-light activated equivalent alone and may be susceptible to colour change with time as a product of the residue of the chemical initiating system. ${ }^{36}$

\section{Post placement finishing}

The final stage for any restoration is finishing the margins of the restoration and any functional contacts to give a smooth and harmonious transition from tooth to restoration. It is particularly important to eliminate any occlusal interferences. The finishing process for porcelain veneers involves using small particle size diamond burs or multi-fluted tungsten carbide burs in either an airotor or a speed accelerating handpiece (Fig. 8). Burs are available in a variety of grit sizes to polish the margins progressively and ideally should be followed by the use of $10 \mathrm{~mm}$ particle size diamond polishing paste to maximise the lustre on the porcelain and the cement lute (Fig. 9). Finishing can also be achieved using rotating abrasive disks that are available for composite resin restorations (eg Soflex discs, Super-Snaps etc).

When finishing the gingival extent of the veneer it is sensible to protect the gingival tissues using a flat plastic instrument. You will want to show the finished result to your patient, 
who will not be impressed if the gingival tissues are lacerated and bleeding! Many operators prefer to delay the detailed finishing until a subsequent appointment at which time any excess material is much easier to identify.

\section{NON-STANDARD VENEERS}

Veneers are generally prescribed for the buccal aspects of maxillary anterior teeth, but there are a number of 'non-standard' applications. These include veneers for:

- The palatal/lingual aspect of teeth which have been worn or fractured

- Diastema elimination using slips restricted to the proximal aspects of teeth

- Lower incisors

- Posterior occlusal onlays

All of these applications require some careful thought to ensure a satisfactory result.

\section{Palatal veneers}

There are two main problems with palatal veneers.

Firstly, it is not possible to adjust the occlusal contacts on the veneer until it is luted in place. This will inevitably result in the need to adjust porcelain in situ. When this is required it is essential that the adjusted porcelain surface be polished with graded abrasives, culminating in diamond paste, to ensure that the opposing teeth are not subject to excessive wear from roughened unglazed porcelain.

Secondly, the finish line for such veneers often extends onto the buccal surface of the tooth. It can be very difficult to disguise that line as the resin luting agent can prove highly visible at the junction between porcelain and tooth (Fig. 10). One option is to try to hide the finish line as much as possible. There are three ways to improve this:

- Never make the finish line a straight line. The human eye is very good at identifying straight lines, but is less good at seeing wavy lines. If the finish line is made serpentinous, using the normal anatomy of the tooth to rise over the mamelons and dip between them, it becomes more difficult to see (Fig. 11).

- Extend the finish line over onto the buccal surface of the tooth significantly. Then ask your technician to gradually increase the quantity of translucent porcelain in the overlapping section so that more and more colour from the restoration is drawn from the tooth and less and less from the veneer. This avoids sudden change in optical properties between tooth and porcelain restoration. (Figs 10,11)

- Use a luting agent that is colour neutral with the tooth so that it blends as much as possible.

\section{Lateral porcelain slips}

There are once again two problems with this sort of porcelain addition, commonly used to obliterate a diastema between teeth.

- Care must be taken to avoid a bulky gingival emergence profile. It is not acceptable to pro-
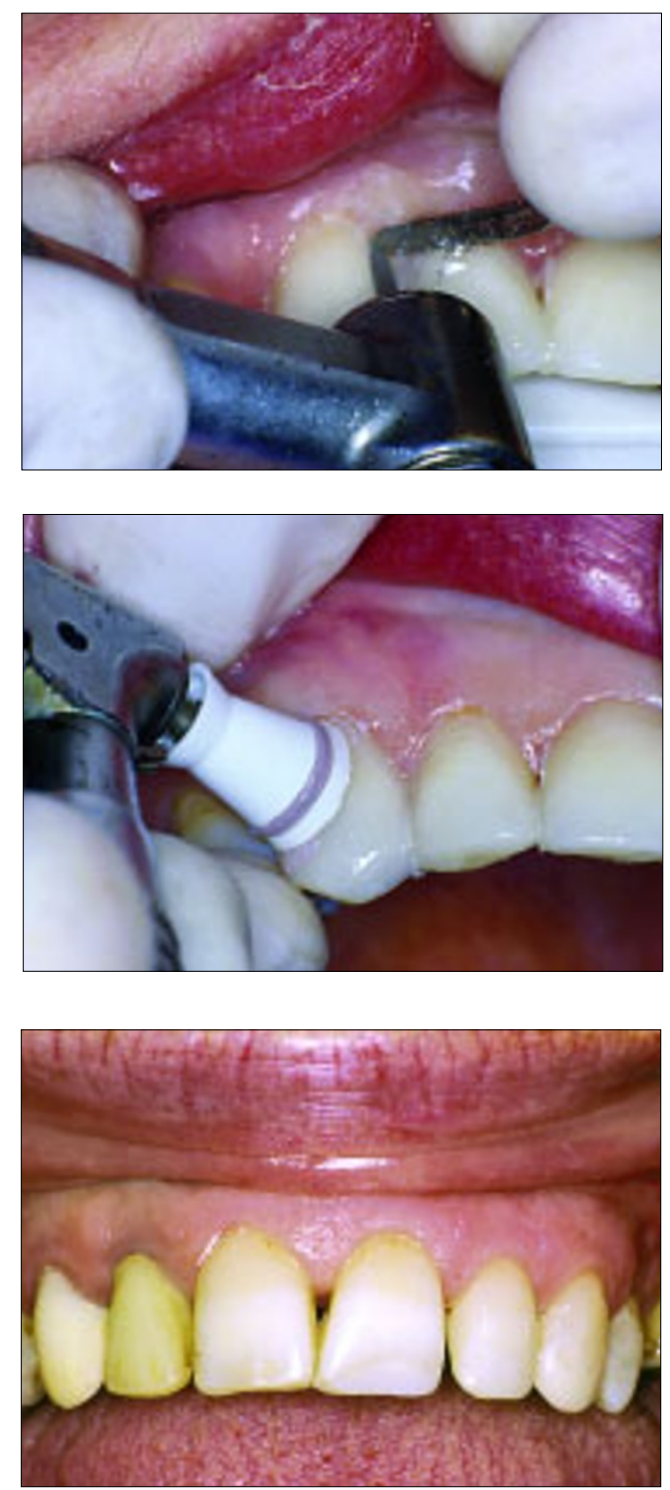

duce artificial overhangs that are not cleansable and are liable to act as plaque traps.

- The junction between porcelain and tooth should be disguised. This is best hidden within the natural anatomy of the tooth by placing the finish line within the intermamelon groove closest to the addition and by using the same concepts as above to blend tooth and porcelain. In this circumstance it may be possible to have a straight finish line, at worst it mimics a crack on the crown surface.

An alternative is simply to extend the veneer over the whole buccal surface with an appropriate extension into the proximal space.

\section{Veneers for mandibular incisors}

Mandibular incisors can be managed with porcelain veneers but the preparation usually has to be extended over the incisal edge of the tooth, particularly if the tooth is in functional contact. The incisal coverage of porcelain has to be sufficiently thick to be durable under continuing rubbing contact with the opposing tooth. This would necessitate incisal edge reduction by between 0.75 and $1 \mathrm{~mm}$. Obviously if the tooth is not temporised there is a risk of over-eruption of
Fig. 8 Finishing the gingival margin of the veneer with a small particle size diamond bur in a speed accelerating handpiece. Once again, a flat plastic instrument protects the gingival tissues

Fig. 9 Final polishing of the gingival margin of the veneer using a rubber cup and diamond polishing paste

Fig. 10 Unsightly, porcelain-tooth junctions at the incisal overlap of the palatal surface veneers at UL1, UL2 and UL3 (21, 22 and 23). The junctions are clearly visible due to the abrupt change in optical contrast and the straight finish line 
Fig. 11 Here the incisal overlap has been hidden. The palatal veneers on UR1 (11) and UL1 (21) have had their incisal margins extended some $2 \mathrm{~mm}$ onto the buccal surface of the tooth with a gradual increase in translucency of the porcelain to improve colour transmission. Also, the finish line is serpentinous

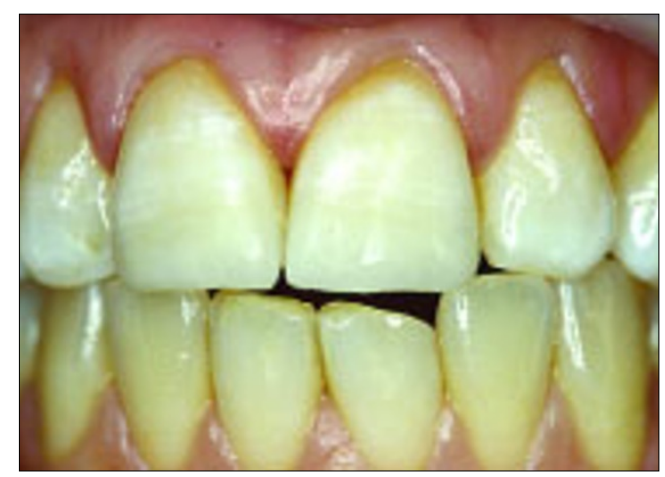

the opposing tooth or the prepared tooth in the period between preparation and fit of the veneers. Space maintenance is best provided by adding composite resin to the palatal surface of the upper teeth to produce a stable occlusal stop between the upper and lower arches, rather than risking damage to the prepared enamel surface of the lower.

\section{Posterior occlusal onlays}

Porcelain occlusal onlays (sometimes termed 'shims') have the potential to offer an elegant and aesthetic means of reconstructing the occlusal surfaces of worn or broken-down teeth. However, despite the initial enthusiasm of some authors $^{37}$ the results with traditional aluminous or feldspathic porcelains have proved disappointing. We have experienced both debonding and fracture, especially when restorations are attached mainly to dentine, and subject to the rigors of bruxism. It may be that one or more of the high strength ceramics would be suitable for this purpose, ${ }^{38}$ but it is too early to make any firm recommendations.

\section{CONCLUSIONS}

Porcelain veneers are a useful adjunct to the armamentarium of the dentist to help in the management of aesthetic problems in patients, both young and old. Care needs to be taken during tooth preparation and particularly during the luting phase to ensure maximal results are obtained for the patient.

1. DPB. Dental Data Digest of Statistics. Dental Practice Board, 1996.

2. DPB. Dental Data Digests of Statistics for 1997 1998,1999,2000 and 2001. Dental Practice Board, 2001.

3. Pincus C. Building mouth personality. Alpha Omega 1948; 42: $163-166$.

4. Horn H R. Porcelain veneers. Dental Clinics of North America 1983; 27: 671-684

5. Dunne S M, Millar B J. A longitudinal study of the clinical performance of porcelain veneers. Br Dent J 1993; 175 317-321.

6. Guidelines. Restorative indications for porcelain veneer restorations. In: Gregg T, editor. Faculty of Dental Surgery National Clinical Guidelines. London: Faculty of Denta Surgeons of Royal College of Surgeons of England, 1997.

7. Peumans $M$, Van Meerbeek B, Lambrechts P, Vanherle G. Porcelain veneers: a review of the literature. J Dent 2000; 28: 163-77.

8. Walls A W G, Murray J J, McCabe J F. Composite laminate veneers: a clinical study. J Oral Rehabil 1988; 15: 439-454.

9. Rucker L M R W, MacEntee M, Richardson A. Porcelain and resin veneers clinically evaluated: 2 -year results. JAm Dent Assoc 1990; 121: 594-596.

10. Harley K E, Ibbetson R J. Anterior veneers for the adolescent patient: 1 General indications and composite veneers. Dent Update 1991; 18: 55-6, 58-9.

11. Welbury R R. A clinical study of a microfilled composite resin for labial veneers. Int J Paed Dent 1991: 1:9-15.

12. Clyde J, Gilmoure A. Porcelain veneers: a preliminary review. BrDent J 1988; 164: 9-14.

13. Strassler $\mathrm{H}$, Nathanson D. Clinical evaluation of etched porcelain veneers over a period of 18-42 months. J Aesthet Dent 1989; 1: 21-28.

14. Nordbo H, Rygh-Thoresen N. Henaug T. Clinical performance of porcelain laminate veneers without incisal overlapping: 3-year results. J Dent 1994; 22: 342-345.

15. Peumans M, Van Meerbeek B, Lambrechts P, VuylstekeWauters M, Vanherle G. Five-year clinical performance of porcelain veneers. Quintessence Int 1998; 29: 211-221.

16. Kihn $P$, Barnes $D$. The clinical evaluation of porcelain veneers: a 48-month clinical evaluation. J Am Dent Assoc 1998; 129: 747-752.

17. Fradeani M. Six-year follow-up with Empress veneers. Int J Periodont Rest Dent 1998; 18: 216-225.

18. Dumfahrt $H_{1}$ Schaffer $H$. Porcelain laminate veneers. A retrospective evaluation after 1 to 10 years of service: Part II-Clinical results. Int J Prosthodont 2000; 13: 9-18.

19. Christensen G, Christensen R. Clinical observations of porcelain veneers. J Aesthet Dent 1991; 3: 174-179.

20. Walls A W. The use of adhesively retained all-porcelain veneers during the management of fractured and worn anterior teeth: Part 2. Clinical results after 5 years of followup. Br Dent J 1995; 178: 337-40.

21. Magne P, Kwon K R, Belser U C, Hodges J S, Douglas W H. Crack propensity of porcelain laminate veneers: A simulated operatory evaluation. J Prosthet Dent 1999; 81: 327-334.

22. Calamia J R. Materials and techniques for etched porcelain facial veneers. Alpha Omega 1988; 81: 48-51.

23. Garber D. Traditional tooth preparation for porcelain laminate veneers. Comp Cont Ed Dent 1991; 12:316, 318, 320, 322.

24. Harley KE, Ibbetson R. Anterior veneers for the adolescent patient: 2 Porcelain veneers and conclusions. Dent Update 1991; 18: 112-116.

25. Nattrass B R, Youngson C C, Patterson C J, Martin D M, Ralph $J$ P. An in vitro assessment of tooth preparation for porcelain veneer restorations. J Dent 1995; 23: 165-170.

26. Hui K, Williams B, Davis E, Holt R. A comparative assessment of the strengths of porcelain veneers for incisor teeth dependent on their design characteristics. Br Dent J 1991; 171: 51-55.

27. Meijering A C Creugers N H, Roeters FJ, Mulder J. Survival of three types of veneer restorations in a clinical trial: a 2.5year interim evaluation. J Dent 1998; 26: 563-568.

28. Calamia J. Materials and techniques for etched porcelain facial veneers. Alpha Omega 1988; 81: 48-51.

29. Sim C, Ibbetson R J. Comparison of fit of porcelain veneers fabricated using different techniques. Int J Prosthodont 1993; 6: 36-42.

30. Raigrodski A J, Sadan A, Mendez A J. Use of a customized rigid clear matrix for fabricating provisional veneers. J Esthet Dent 1999; 11: 16-22.

31. Swift B, Walls A W, McCabe J F. Porcelain veneers: the effects of contaminants and cleaning regimens on the bond strength of porcelain to composite. Br Dent J 1995; 179: 203-208.

32. Strang R, McCrossan J, Muirhead M, Richardson S. The setting of visible light cured resins beneath etched porcelain veneers. Br Dent J 1987; 163: 149-151.

33. Warren K. An investigation into the microhardness of a lightcured composite when cured through varying thicknesses of porcelain. J Oral Rehabil 1990; 17: 327-334.

34. O'Keefe $K$, Pease $P$, Herren $H$. Variables affecting the spectral transmittance of porcelain through porcelain veneer samples. J Prosthet Dent 1991; 66: 434-438.

35. Linden J J, Swift E J, Jr., Boyer D B, Davis B K. Photo-activation of resin cements through porcelain veneers. J Dent Res 1991; 70: $154-157$

36. Berrong J M, Weed R M, Schwartz I S. Color stability of selected dual-cure composite resin cements. J Prosthodont 1993; 2: 24-27

37. Mabrito C, Roberts M. Porcelain onlays. Curr Opin Cosmetic Dent 1995: 1-8.

38. Denissen H, Dozic A, van der Zel J, van Waas M. Marginal fit and short-term clinical performance of porcelain-veneered CICERO, CEREC, and Procera onlays. J Prosthet Dent 2000; 84: 506-13. 